\title{
Territorial aggression reduces vigilance but increases aggression towards predators in a cooperatively breeding fish
}

\section{Sybille Hess ${ }^{1,2},{ }^{*}$ Stefan Fischer ${ }^{1,3,4} \&$ Barbara Taborsky ${ }^{1}$}

${ }^{1}$ Division of Behavioural Ecology, Institute of Ecology and Evolution, University of Bern, Wohlenstrasse 50A, 3032 Hinterkappelen, Switzerland

${ }^{2}$ School of Marine and Tropical Biology, James Cook University, Townsville, Queensland, 4811, Australia

${ }^{3}$ Department of Zoology, University of Cambridge, United Kingdom

${ }^{4}$ Institute of Integrative Biology, University of Liverpool, Liverpool L69 7ZB, UK

*Corresponding author: Stefan Fischer (stefanfischer@gmx.at, +44 151794 6007)

Short title: Effects of aggressive interactions on anti-predator behaviours

Word count: 6315 
In many species, aggressive individuals outcompete their less aggressive conspecifics for resources such as food and access to mates. Nevertheless, variation in aggression is maintained in populations, but the underlying mechanisms are not well understood. Here we tested the hypothesis that aggressive behaviours compromise the anti-predator behaviour of prey, which would link aggressive behaviours to a cost of predation. We presented computeranimated images of predators to the cooperatively breeding cichlid fish Neolamprologus pulcher either during territorial contests with a group of territory intruders or when being alone. We investigated their response latencies and the behaviour directed towards predator images. (i) We found that test fish responded to the predator images significantly later during territorial contests than when they were alone. Moreover during territorial contests, response latencies of test fish increased with increasing levels of aggression towards conspecifics. (ii) Test fish responded more aggressively to the predator images during territorial contests than when they were alone. During territorial contests, fish that responded later towards the predator images were more aggressive towards these images. Our findings suggest that territorial contests compromised the ability of prey to show fast responses towards predators. However, we propose that enhanced aggression towards predators might increase survival chances of prey during predator encounters in nature, and it may thus compensate for costs incurred by delayed predator responses during territorial contests. To test this hypothesis experiments under natural predation regimes that examine the relationship between predation risk, territorial and anti-predator aggression are required.

Keywords: anti-predator behaviour, cichlid fish, computer animation, predation risk, territory defence, trade-off 
Aggression is an important fitness trait in various species (e.g. Biro \& Stamps 2008; Riebli et al., 2011; Smith \& Blumstein 2008). The ability to defend a territory, compete aggressively for mates or achieve a high social rank in a dominance hierarchy is often vital for reproductive success (Peiman \& Robinson 2010; Shackleton, Jennings \& Hunt 2005). Accordingly, there is ample evidence that aggressive individuals have a higher reproductive success than their less aggressive conspecifics (Biro \& Stamps 2008; Smith \& Blumstein 2008). Based on this, populations would be expected to become increasingly aggressive. However, studies on animal personality revealed that the levels of aggression maintained within populations are highly variable (Sih, Bell \& Johnson 2004). The underlying mechanisms that are responsible for the maintenance of the observed variation in aggression, however, are not yet well understood.

It has been suggested that aggressive individuals suffer an increased predation risk (Quinn \& Cressell 2005; Sih et al., 2004; Smith \& Blumstein 2008). Aggressive interactions between conspecifics require a high level of attention (Brick 1998; Jakobsson, Brick \& Kullberg 1995), and may distract individuals from other attention-consuming tasks that are carried out simultaneously, such as vigilance (Brick 1998; Clark \& Dukas 2003; Dukas \& Kamil 2000; Dunn, Copelston \& Workman 2004; Jakobsson et al., 1995). Vigilance increases the likelihood of detecting a predator before or early during an attack, reducing predation risk (Cresswell 1994; Cresswell, Quinn, Qhittingham \& Butler 2003; Lima \& Bednekoff 1990; Lima \& Dill 1990). Aggressive behaviour may therefore result in a cost of predation by compromising vigilance, which may contribute to the maintenance of different levels of aggression in a population (Sih et al., 2004). However, anti-predator behaviours other than vigilance are likely to influence prey survival during a predator encounter as well, such as the reaction of prey to the predator after detection. These anti-predator behaviours have received little attention, but are important to consider when examining predator-prey interactions. 
In the present study we exposed the cooperatively breeding cichlid Neolamprologus pulcher to computer-animated images of predators and investigated how aggressive interactions during territorial contests affect predator detection. $N$. pulcher has been shown to recognize animated 2-D images of L. elongatus as predators and to respond accordingly (Fischer et al., 2014). Using animated pictures allowed us to standardize predator behaviour and apprearance and thereby the perceived threat posed by the predator. In the field, dominant breeder pairs of $N$. pulcher and their subordinate brood helpers defend a territory against conspecific intruders that attempt to enter the territory (Sturmbauer et al., 2008; Taborsky \& Limberger 1981). Territorial contests can be intense and can include threat displays and overt attacks (Hirschenhauser, Taborsky, Oliveira, Canario \& Oliveira 2004). The number of attacks directed towards intruders is repeatable in this species and is an indication of an individual's inherent aggression (Schürch \& Heg 2010; Witsenburg, Schürch \& Heg 2010). In the field, individuals are under intense predation risk, in particular by the piscivorous predator Lepidiolamprologus elongatus that lurks around N. pulcher territories (Heg, Bachar, Brouwer \& Taborsky 2004; Hori, Yamaoka \& Takamura 1983). N. pulcher is therefore a suitable model species to study the relationship between vigilance and aggressive interactions between conspecifics.

This study pursued two aims; (1) examining the influence of territorial contests between a territory owner and a group of intruders on the owner's vigilance; and (2) examining the influence of territorial contests on the owner's response towards predators. We used the time until the owner detected the predator (response latency) as a measure of its vigilance. We compared the owner's vigilance between a treatment allowing for territorial contests and a control situation when the territory owner was alone. We predicted that territory owners would reduce their vigilance during territorial contests, i.e. that they would detect the approaching predator later during territorial contests than when alone. We further 
hypothesized that responses by territory owners towards the predator will not only occur with some delay but will also be attenuated during contests.

\section{METHODS}

Study subjects

N. pulcher and its main predator L. elongatus, a voracious piscivore (Heg et al., 2004; Hori et al., 1983), are both lamprologine cichlids endemic to Lake Tanganyika (Konings, 1998). N. pulcher inhabits sandy to rocky habitats along the shoreline from 3 to above $45 \mathrm{~m}$ depth (Duftner et al., 2007; Taborsky, 1984). This species typically lives in social groups of 3 to 25 individuals, consisting of a dominant breeder pair and subordinate brood care helpers, but in some cases single adult individuals defend a small territory (Heg, Brouwer, Bachar \& Taborsky 2005; Taborsky \& Limberger, 1981).

\section{Ethical note}

The study was done under license 52/12 of the Veterinary Service of the Canton Bern, Switzerland. All N. pulcher used in this study and the specimens of L. elongatus used to produce computer animations were derived from the laboratory breeding stocks kept at the Division of Behavioural Ecology, University of Bern, under standardized housing conditions (see Arnold \& Taborsky 2010). To prevent injuries, territory owners and intruders were kept in adjacent tanks and had only visual contact. Pictures of predators were used to simulate predation threat, rather than live predators, in order to reduce the number of animals used in the experiment. To avoid stress, handling time of $N$. pulcher and L. elongatus was kept to a minimum. At the end of the experiment, all fish were returned to their original stock tank.

\section{Production of animations}


We used six specimens of $L$. elongatus to create animated 2-D predator images, following the methods outlined in Fischer et al. (2014). In brief, we took photographs (camera: Nikon Coolpix 995, $200 \mathrm{~mm}$ lens) of the lateral side of each L. elongatus and then cut out the body shape using the image editing software Gimp (Mattis \& Kimball, 1995). The 2-D images were fitted to a size of $16 \mathrm{~cm}$ standard length, and used to create six Power Point presentations (one for each specimen). A Power Point presentation consisted of nine animations (i.e. nine different Power Point slides) with a greenish background resembling turbid lake water, and images of stones in the front. The stones (width: $6 \mathrm{~cm}$, height: $5 \mathrm{~cm}$ ) served as size-reference relative to the fish images (Baldauf, Kullman \& Bakker 2008). For each of the nine animations of a given presentation, the same image of a L. elongatus entered the screen from the right side at a height of $5 \mathrm{~cm}$, moved across the screen at a speed of $1 \mathrm{~cm} \mathrm{sec}^{-1}$ and left the screen on the opposite side. The image was visible for $25 \mathrm{sec}$. The L. elongatus image of the first animation (i.e. the first Power Point slide) was always the most difficult to detect, with the animations in the following Power Point slides gradually increasing in detectability. For this purpose, we covered the fish images with an additional layer that had the same shape as the fish and a colour identical to the background. With each Power Point slide, the transparency value of the layer increased $(<1 \%$ in the first slide, $1 \%, 3 \%, 5 \%, 7 \%, 9 \%, 11 \%$, $15 \%$, and $20 \%$ in the ninth slide), imitating decreasing degrees of water turbidity and thus increasing visibility. For each transparency value all major features such as eyes, mouth, fins and body shape of the presented fish were clearly discernible. During each test, we recorded the first slide during which the test fish detected the predator (i.e. slide 1 - 9). The Power Point presentations of the six specimens were randomly assigned to the test fish.

\section{Experimental set-up}

The experimental set-up consisted of two tanks $(40 \mathrm{~cm} \times 25 \mathrm{~cm}$ x $25 \mathrm{~cm})$ separated by an opaque divider (Fig. 1, divider not shown). The bottom of both tanks was covered by a $2 \mathrm{~cm}$ 
layer of gravel. The tank of the test fish (tank 1) contained a shelter, which was placed in the third of tank 1, which was closest to tank 2 and farthest away from the computer screen (further referred to as first third of tank 1; Fig. 1). The side towards the screen was covered by a paper copy of the Power Point slides' background to habituate the test fish to the greenish background and the stone images. The second tank (tank 2) held either a group of conspecifics or was empty, depending on the treatment (see below). All walls of tank 2, except the wall facing tank 1 , were shielded by black PVC sheets.

The test fish $(N=28,2.0-4.0 \mathrm{~cm}$ standard length $)$ were haphazardly caught from the institute's breeding stock one day before the experiment started and placed in the experimental tank. One day is sufficient for juvenile $N$. pulcher to establish a territory if provided with a shelter (Arnold \& Taborsky, 2010). All test fish were exposed to two treatments in randomized order: (1) The 'territorial contest' treatment, in which a group of four conspecifics was placed in tank 2. These four individuals were collected from the stock population the day before the trial and were left to habituate in the experimental tank overnight. The sizes of these individuals were chosen to be within $\pm 0.5 \mathrm{~cm}$ of the test fish, with some individuals being smaller and some larger than the focal individual. Each group of four fish was used only once to avoid pseudoreplication. We chose a group of conspecifics for the territorial contest treatment because, in $N$. pulcher, often several fish are involved in aggressive interactions with territory owners; for instance, when owners encounter neighbouring group members at the territory border or when intruders invade a territory (Taborsky \& Limberger, 1981). Experiments where conspecific intruders are exposed to test fish behind clear partitions have been commonly performed in $N$. pulcher in order to standardize the presentation of conspecifics (e.g. Desjardins, Fitzpatrick \& Balshine 2008; Hirschenhauser et al., 2004). (2) In the control treatment test fish were exposed to tank 2 without any fish. 
On the day of the experiment, we placed a flat screen monitor (Compaq 1520, with 15" and 1024 x 768 pixels) on the right side of tank 1 (see Fig. 1). Then we removed the paper copy and allowed the test fish to acclimatize to the screen and to the observer, who sat motionless with a laptop in front of both tanks for $10 \mathrm{~min}$. In a pilot study we found that test fish were not irritated or distracted by the presence of the observer, and this observation method was also used successfully in previous studies (e.g. Fischer et al., 2014). After the acclimation phase the observer removed the divider that visually separated the two tanks. Because tank 2 was covered by PVC sheets, the observer could only see the behaviour of the test fish in tank 1, and was thus not distracted by the behaviour of the fish in tank 2 during the 'territorial contest' treatment. Typically, the test fish entered the shelter while the observer removed the divider, but left it immediately afterwards. The first animation was started once the test fish was out of the shelter and within the first third of the tank (which was marked by a permanent pen on the front screen of the tank; see Fig. 1) and directed its head towards the second tank, i.e. it faced diametrically away from the animation (Fig. 1). Each animation took 2 min, during which the predator image and its background was visible for 25 s. Correspondingly, for $95 \mathrm{~s}$ only the background was visible. We recorded all behaviours (attack, attention, freezing, threat displays and hiding; for details on the behaviour, see Fischer et al., 2014) of the test fish during the entire 2 min using the observation software Observer 5.0 (Noldus Information Technology), i.e. also after the predator image was no longer visible. Test fish were considered to have detected the predator image (i) if an abrupt change of behaviour occurred, such as freezing, hiding or aggressive displays (fin spread, head down position, approach or overt attacks (Hamilton, Heg \& Bender 2005; Taborsky 1982) towards the computer screen, (ii) if they directed their attention towards the screen while the predator image was visible (i.e. within $25 \mathrm{~s}$ ). They could do so by quickly changing their body position such that they were facing the animation, or by following the pathway of the animation. After 
the 2 min had passed, the next animation was started, again only once the test fish directed its head towards the second tank, was out of the shelter and within the first third of the tank. This was repeated for all nine animations (i.e. the behaviour was recorded for $9 \times 2 \mathrm{~min}$ ). After the trials of the first treatment, the test fish were left undisturbed in the experimental tank until the next day when they were exposed to the second treatment, for which we followed the same procedures as described above.

\section{Statistical analysis}

For statistical analysis we used R 3.0.2 (R Core Development Team 2013) with the package 'Ime4' (Bates, Maechler \& Bolker 2011). To account for the within-subject design and the sequence order of the treatments we used linear mixed models (LMM) and generalized linear mixed models (GLMM). In all analyses size of the test fish was included as a covariate and the sequence order of the treatments as a random factor. To assess whether the response of the test fish towards the predator was influenced by territorial aggression against the neighbouring group of conspecifics we performed a LMM with individual identity as an additional random factor, the latency to respond towards the predator (further referred to as 'response latency' or 'latency to first response') as a dependent variable and treatment (territorial contest vs. control treatment) as fixed factor. To calculate the response latencies (in seconds) only the 25 -s periods when the predator image was visible were considered. We first noted the order number of the animation (i.e. slides 1 through to 9) at which test fish responded the first time towards the predator (further referred to as 'AFR' or 'animation of first response'). We further recorded the time (in seconds) until the first behavioural reaction towards the AFR occurred. To obtain a response latency in a given trial we multiplied the number of animations without a response (i.e. AFR-1) by 25 (i.e. the duration a predator was visible on each animation) and added the seconds until first reaction towards the AFR to the resulting product. 
To assess the first response towards the predator in all presented animations we fitted a GLMM with individual identity included as an additional random factor and a logit link to account for a binomial error structure. All fish responded to the predator either by fear behaviour (hiding or freezing), or by aggressive displays. To compare their probability to respond aggressively towards the predator between treatments, we assigned each individual to one of two categories of a binary variable, 'aggressive' (first response was an aggressive behaviour) or 'non-aggressive' (first response was a fear behaviour). To better understand why test fish detected the predator later and responded more aggressively during the territorial contest treatment (see Results), we conducted two post-hoc analyses, which used only the data obtained from the territorial contest treatment. First, we did an LMM to test for the effect of the number of attacks directed towards the conspecific group during the first animation (i.e. representing the aggression that each fish displayed within the first 2 min of each trial) on the latency to first response. Second, we fitted a GLMM with a logit link function to account for a binomial error structure to test for the effects of response latency and number of attacks towards conspecifics on the probability of responding aggressively towards the predator.

Residuals and Q/Q-plots of all LMM were visually inspected and the distributions of residuals were compared to a normal distribution using Kolmogorov-Smirnov and Shapiro tests. In all models we square-root transformed the variables 'response latency' and 'aggression towards conspecifics'. Significance testing was based on deviance when removing respective terms from the model. The change in log-likelihood was compared to a chi-square distribution (see Crawley 2007). 


\section{RESULTS}

\section{Vigilance}

The test fish responded later to the animated predator image in the presence of a group of conspecifics than when they were alone (Table 1, Fig. 2a). The post-hoc analysis of the territorial contest treatment revealed that response latencies were longer and thus the predator image was detected later with increasing aggression directed towards the group of conspecifics (Table 1, Fig. 2b). Moreover, smaller test fish tended to detect the predator later (see negative estimate of factor 'size' in Table 1).

\section{Behavioural responses to predator animations}

Test fish showed a higher probability to respond aggressively (i.e. fin spread or attack) to the predator image in the presence of territorial intruders than when they were alone (Table 1, Fig. 3a). In addition, large test fish had a higher probability to respond aggressively to the predator image than small fish in both treatments (Table 1, Fig. 3a). Interestingly, the posthoc analysis of the territorial contest treatment revealed that test fish that detected the predator later behaved more aggressively towards the predator animation (see factor 'latency' in Table 1, Fig. 3b). There was no relationship between the aggression towards the predator and the number of attacks towards the conspecific intruders (Table 1). Again, larger test fish were more aggressive towards the predator than smaller test fish when conspecific intruders where present (Table 1).

\section{DISCUSSION}

$N$. pulcher responded later and more aggressively to a predator animation during territorial contests than when alone. Moreover, we found a positive relationship between conspecific aggression and the latency to first response. In addition, fish were more aggressive towards the predator the later they had detected it. 
Our results suggest that aggressive interactions with territorial intruders compromise the ability of fish to monitor their surroundings for predators. A trade-off between the attention directed towards territory intruders and vigilance may thus exist. This is in line with previous findings in willow warblers (Jakobsson et al., 1995), convict cichlids (Brick 1998), and European robins (Dunn et al., 2004). In contrast to earlier studies, in our experiment territory owners were interacting with a group rather than a single conspecific. It is well known that groups are quicker in detecting predators than single individuals (Cresswell 1994). The fact that the conspecific $N$. pulcher group slowed down rather than enhanced predator detection further emphasizes the increased costs caused by predation risk during aggressive interactions.

Alternatively, territory owners may have detected the predator during territorial contests as early as in the control, but may have delayed their predator response (Cooper 2009; Cooper \& Frederick 2007; Yee, Desowity \& Blumstein 2013). A delayed response would allow territory owners to assess the threat posed by the predator in order to avoid unnecessary escapes, which could result in the loss of their territory (LaManna \& Eason 2007). However, in contrast to previous studies that only recorded the escape of test individuals (Brick 1998, Dunn et al. 2004; Jakobsson et al., 1995), in the present study all behaviours that indicate predator detection were examined (e.g. sudden change in behaviour, turning away from the intruders and towards the computer screen, freezing, fin spread etc.). It seems unlikely that test fish would detect a predator without displaying any change in behaviour (Cooper \& Sherbrooke 2015). Therefore, a trade-off between aggression and vigilance better supports our results than a delay in predator response. 
In $N$. pulcher the number of aggressive behaviours directed towards intruders in a standardized setting is an indication for an individual's inherent level of aggressiveness (Balzarini, Taborsky, Wanner, Koch \& Frommen 2014; Schürch \& Heg 2010; Witsenburg et al., 2010). Our findings may therefore suggest that aggressive individuals are in general less vigilant than less aggressive individuals. Under such a scenario, aggressive individuals would favour territorial defence over vigilance, i.e. reproduction over survival, while less aggressive individuals would do the opposite. Both strategies may result in equal fitness (Quinn \& Cressell 2005; Sih et al., 2004; Smith \& Blumstein 2008). However, in our laboratory setting we could not test if being less vigilant also translates into an increased predation risk.

In contrast to our prediction, $N$. pulcher reacted more aggressively towards the predator during territorial contests than when they were alone. Different ultimate and proximate reasons may explain this unexpected effect. First, an aggressive predator response may serve as a strategy to compensate for reduced vigilance and the ensuing delayed predator detection during territorial contests. The predator image in our study increased in visibility over time (resembling a fish appearing progressively closer in murky water; see 'Methods'). As a consequence, fish that detected the predator image later may have perceived it as being closer to the territory than fish detecting the image earlier during the treatment. Our result thus indicate that it may be beneficial to hide or freeze when a predator is further away (and may have not yet detected the prey), and to respond aggressively when a predator is already close, as a last resort to evade predation when a successful escape seems unlikely. This explanation is supported by a positive correlation between aggressiveness towards the predator and latency to respond in the territorial contest treatment.

Second, the presence of conspecifics may have increased the perceived population density. Neighbouring $N$. pulcher groups in the wild jointly defend against predators, and predation 
risk decreases as population density increases (Jungwirth \& Taborsky 2015). A lower predation risk in turn might imply lower costs to respond aggressively to predators. A recent study shows, however, that territory owners reduce rather than increase their attack rates against predators as population density increases (Jungwirth, Josi, Walker \& Taborsky 2015). Hence, it is unlikely that a higher perceived population density was the driver of our results.

Third, territory owners may have responded more aggressively to the predator image to signal their superior physical fitness to the territorial intruders (Doutrelant et al., 2001). Individuals are known to change their behaviour in the presence of observing conspecifics in order to deter potential competitors (audience effect; Doutrelant, McGregor \& Oliveira 2001). For instance, subordinate African cichlids fought more aggressively when other subordinates were watching (Desjardins et al., 2012). Increased aggression towards the predator may thus have served as a signal of competitiveness directed to the conspecific intruders.

As a potential proximate mechanism, the aggressive interactions with conspecifics might have had carry-over effects on the level of aggression directed towards the predator image. In fish, aggressive encounters can increase the level of aggression displayed in future encounters with conspecifics (reviewed in Hirschenhauser \& Oliveira 2006; Oliveira et al. 2009). It is not known if an increase in aggression as a result of territorial contests can have similar carryover effects to interactions with predators. Even though aggression towards conspecifics and towards predators were not correlated in our study, a carry-over effect may indeed exits as test individuals competing against intruders were also more aggressive towards predators than were test individuals in the control situation.

Small territory owners were less aggressive towards the predator than large individuals (Table 1). N. pulcher is known to attack predators to defend their brood and other group members 
(Taborsky 1984). Our result indicates that the predator image used in this study posed a greater threat to small compared to large individuals (Helfman 1989). This was expected as $L$. elongatus is a gape-size limited predator and smaller N. pulcher are predated by a broader size range of predators (Hellig, Kerschbaumer, Sefc \& Koblmüller 2010).

\section{Conclusions}

Our results support the existence of a behavioural trade-off between territory defence and vigilance in $N$. pulcher, which highlights a potential mechanism to maintain behavioural variability of these traits within populations. However, responding aggressively to a predator may represent an alternative anti-predator strategy to being vigilant, which may increase survival during a predator encounter, particularly when the predator is already nearby. Whether the vigilance-aggression trade-off results in individuals with higher aggressive tendencies paying a cost of predation and contributes to the maintenance of different personality types in a population is therefore not yet known. Further studies are needed that measure individual predation risk in relation to vigilance and territorial aggression and antipredator aggression under natural predation regimes.

\section{Acknowledgements}

We would like to thank Sander van Doorn for help with the experimental randomization process, Leif Engqvist for statistical advice, and Evi Zwygart for logistic support. Comments by Bob Elwood and two anonymous reviewers helped to greatly improve the manuscript. We are grateful for financial support by the Swiss National Science Foundation (SNSF grants 31003A_156881 to B.T. and P2BEP3_155614 to S.F.) and the Fondation Pierre Mercier. 


\section{REFERENCES}

Arnold, C., \& Taborsky, B. (2010). Social experience in early ontogeny has lasting effects on social skills in cooperatively breeding cichlids. Animal Behaviour, 79(3), 621-630.

Baldauf, S. A., Kullmann, H., \& Bakker, T. (2008). Technical Restrictions of ComputerManipulated Visual Stimuli and Display Units for Studying Animal Behaviour. Ethology, 114(8), 737-751.

Balzarini, V., Taborsky, M., Wanner, S., Koch, F., \& Frommen, J. G. (2014). Mirror, mirror on the wall: the predictive value of mirror tests for measuring aggression in fish. Behavioral ecology and sociobiology, 68(5), 871-878.

Bates, D., Maechler, M. \& Bolker, B. (2011). lme4: Linear mixed-effects model using S4 classes. R package version 0.999375-42, http://cran.r-project.org/package=lme4.

Biro, P. A., \& Stamps, J. A. (2008). Are animal personality traits linked to life-history productivity?. Trends in Ecology \& Evolution, 23(7), 361-368.

Bolker, B. M., Brooks, M. E., Clark, C. J., Geange, S. W., Poulsen, J. R., Stevens, M. H. H., \& White, J. S. S. (2009). Generalized linear mixed models: a practical guide for ecology and evolution. Trends in ecology \& evolution, 24(3), 127-135.

Brick, O. (1998). Fighting behaviour, vigilance and predation risk in the cichlid fish Nannacara anomala. Animal Behaviour, 56(2), 309-317. 
Carter, A. J., Goldizen, A. W., \& Tromp, S. A. (2010). Agamas exhibit behavioral syndromes: bolder males bask and feed more but may suffer higher predation. Behavioral Ecology, 21(3), $655-661$.

Chan, A. A. Y. H., Giraldo-Perez, P., Smith, S., \& Blumstein, D. T. (2010). Anthropogenic noise affects risk assessment and attention: the distracted prey hypothesis. Biology Letters, $6(4), 458-461$.

Clark, C. W., \& Dukas, R. (2003). The behavioral ecology of a cognitive constraint: limited attention. Behavioral Ecology, 14(2), 151-156.

Cooper Jr, W. E. (2009). Flight initiation distance decreases during social activity in lizards (Sceloporus virgatus). Behavioral Ecology and Sociobiology, 63(12), 1765-1771.

Cooper, W. E., \& Frederick, W. G. (2007). Optimal flight initiation distance. Journal of theoretical biology, 244(1), 59-67.

Cooper Jr, W. E., \& Sherbrooke, W. C. (2015). Monitoring by prey that does not reveal awareness by turning toward approaching predators. Behavioral Ecology and Sociobiology, 69(8), 1377-1382.

Crawley, M. J. (2007). The R book. West Sussex, U.K.: John Wiley \& Sons Ltd.

Cresswell, W. (1994). Flocking is an effective anti-predation strategy in redshanks, Tringa totanus. Animal behaviour, 47(2), 433-442. 
Cresswell, W., Quinn, J. L., Whittingham, M. J., \& Butler, S. (2003). Good foragers can also be good at detecting predators. Proceedings of the Royal Society of London B: Biological Sciences, 270(1519), 1069-1076.

Desjardins, J. K., Stiver, K. A., Fitzpatrick, J. L., \& Balshine, S. (2008). Differential responses to territory intrusions in cooperatively breeding fish. Animal Behaviour, 75(2), 595604.

Doutrelant, C., McGregor, P. K., \& Oliveira, R. F. (2001). The effect of an audience on intrasexual communication in male Siamese fighting fish, Betta splendens. Behavioral Ecology, 12(3), 283-286.

Duftner, N., Sefc, K. M., Koblmüller, S., Salzburger, W., Taborsky, M., \& Sturmbauer, C. (2007). Parallel evolution of facial stripe patterns in the Neolamprologus brichardi/pulcher species complex endemic to Lake Tanganyika. Molecular phylogenetics and evolution, 45(2), 706-715.

Dukas, R., \& Kamil, A. C. (2000). The cost of limited attention in blue jays. Behavioral Ecology, 11(5), 502-506.

Dunn, M., Copelston, M., \& Workman, L. (2004). Trade-offs and seasonal variation in territorial defence and predator evasion in the European Robin Erithacus rubecula. Ibis, 146(1), 77-84. 
Earley, R. L. (2010). Social eavesdropping and the evolution of conditional cooperation and cheating strategies. Philosophical Transactions of the Royal Society of London B: Biological Sciences, 365(1553), 2675-2686.

Fischer, S., Taborsky, B., Burlaud, R., Fernandez, A. A., Hess, S., Oberhummer, E., \& Frommen, J. G. (2014). Animated images as a tool to study visual communication: a case study in a cooperatively breeding cichlid. Behaviour, 151(12-13), 1921-1942.

Hamilton, I. M., Heg, D., \& Bender, N. (2005). Size differences within a dominance hierarchy influence conflict and help in a cooperatively breeding cichlid. Behaviour, 142(11-12), 15911613.

Heg, D., Bachar, Z., Brouwer, L., \& Taborsky, M. (2004). Predation risk is an ecological constraint for helper dispersal in a cooperatively breeding cichlid. Proceedings of the Royal Society of London B: Biological Sciences, 271(1555), 2367-2374.

Heg, D., Brouwer, L., Bachar, Z., \& Taborsky, M. (2005). Large group size yields group stability in the cooperatively breeding cichlid Neolamprologus pulcher. Behaviour, 142(1112), 1615-1641.

Hellig, C. J., Kerschbaumer, M., Sefc, K. M., \& Koblmüller, S. (2010). Allometric shape change of the lower pharyngeal jaw correlates with a dietary shift to piscivory in a cichlid fish. Naturwissenschaften, 97(7), 663-672. 
Hirschenhauser, K., Taborsky, M., Oliveira, T., Canario, A. V., \& Oliveira, R. F. (2004). A test of the 'challenge hypothesis' in cichlid fish: simulated partner and territory intruder experiments. Animal Behaviour, 68(4), 741-750.

Hori, M., Yamaoka, K., \& Takamura, K. (1983). Abundance and micro-distribution of cichlid fishes on a rocky shore of Lake Tanganyika.

Jakobsson, S., Brick, O., \& Kullberg, C. (1995). Escalated fighting behaviour incurs increased predation risk. Animal Behaviour, 49(1), 235-239.

Jones, K. A., \& Godin, J. G. J. (2010). Are fast explorers slow reactors? Linking personality type and anti-predator behaviour. Proceedings of the Royal Society of London B: Biological Sciences, 277(1681), 625-632.

Jungwirth, A., Josi, D., Walker, J., \& Taborsky, M. (2015). Benefits of coloniality: communal defence saves anti-predator effort in cooperative breeders. Functional Ecology.

Jungwirth, A. \& Taborsky, M. (2015). First and second order sociality determine survival and reproduction in cooperative cichlids. Proceedings of the Royal Society B, 282, 20151971.

Konings, A. (1998). Tanganyika cichlids in their natural habitat. Ettlingen: Cichlid Press.

Kralj-Fišer, S., Weiß, B. M., \& Kotrschal, K. (2010). Behavioural and physiological correlates of personality in greylag geese (Anser anser). Journal of Ethology, 28(2), 363-370. 
Lind, J., \& Cresswell, W. (2005). Determining the fitness consequences of antipredation behavior. Behavioral Ecology, 16(5), 945-956.

Mattis, P. \& Kimball, S. (1995). Gnu image manipulation program (Version 0.1.12) [Image Editor]. Retrieved from http://www.gimp.org/

Oliveira, R. F., McGregor, P. K., \& Latruffe, C. (1998). Know thine enemy: fighting fish gather information from observing conspecific interactions. Proceedings of the Royal Society of London B: Biological Sciences, 265(1401), 1045-1049.

Pascual, J., \& Senar, J. C. (2014). Antipredator behavioural compensation of proactive personality trait in male Eurasian siskins. Animal Behaviour, 90, 297-303.

Peiman, K., \& Robinson, B. (2010). Ecology and evolution of resource-related heterospecific aggression. The Quarterly Review of Biology, 85(2), 133-158.

R Core Development Team. (2012). R: A language and environment for statistical computing (Version 3.2.2). Retrieved from http://cran.r-project.org/.

Riebli, T., Avgan, B., Bottini, A. M., Duc, C., Taborsky, M., \& Heg, D. (2011). Behavioural type affects dominance and growth in staged encounters of cooperatively breeding cichlids. Animal Behaviour, 81(1), 313-323.

Schürch, R., \& Heg, D. (2010). Life history and behavioral type in the highly social cichlid Neolamprologus pulcher. Behavioral Ecology, 21(3), 588-598. 
Shackleton, M. A., Jennions, M. D., \& Hunt, J. (2005). Fighting success and attractiveness as predictors of male mating success in the black field cricket, Teleogryllus commodus: the effectiveness of no-choice tests. Behavioral Ecology and Sociobiology, 58(1), 1-8.

Sih, A., Bell, A., \& Johnson, J. C. (2004a). Behavioral syndromes: an ecological and evolutionary overview. Trends in ecology \& evolution, 19(7), 372-378.

Smith, B. R., \& Blumstein, D. T. (2008). Fitness consequences of personality: a metaanalysis. Behavioral Ecology, 19(2), 448-455.

Sturmbauer, C., Fuchs, C., Harb, G., Damm, E., Duftner, N., Maderbacher, M., ... \& Koblmüller, S. (2009). Abundance, distribution, and territory areas of rock-dwelling Lake Tanganyika cichlid fish species. In Patterns and Processes of Speciation in Ancient Lakes (pp. 57-68). Springer Netherlands.

Taborsky, M. (1982). Brutpflegehelfer beim Cichliden Lamprologus brichardi, Poll (1974): Eine Kosten/Nutzen Analyse. (Doctoral dissertation). University of Vienna, Austria.

Taborsky, M. (1984). Broodcare helpers in the cichlid fish Lamprologus brichardi: their costs and benefits. Animal Behaviour, 32(4), 1236-1252.

Taborsky, M., \& Limberger, D. (1981). Helpers in fish. Behavioral Ecology and Sociobiology, 8(2), 143-145. 
Witsenburg, F., Schürch, R., Otti, O., \& Heg, D. (2010). Behavioural types and ecological effects in a natural population of the cooperative cichlid Neolamprologus pulcher. Animal Behaviour, 80(4), 757-767.

Wolf, M., Van Doorn, G. S., Leimar, O., \& Weissing, F. J. (2007). Life-history trade-offs favour the evolution of animal personalities. Nature, 447(7144), 581-584.

Yee, J., Lee, J., Desowitz, A., \& Blumstein, D. T. (2013). The Costs of Conspecifics: Are Social Distractions or Environmental Distractions More Salient? Ethology, 119(6), 480-488. 


\section{Table 1}

Analyses of treatment effects and post-hoc analyses of behaviour during territorial contests.

\begin{tabular}{lcccc}
\hline Factor & Estimate \pm SE & df & Chi $^{2}$-Value & $P$-value \\
\hline Latency & & & & \\
Intercept & $5.362 \pm 1.956$ & - & - & - \\
Treatment & $3.265 \pm 0.689$ & 1 & 18.757 & $<\mathbf{0 . 0 0 1}$ \\
Size & $-0.281 \pm 0.616$ & 1 & 0.169 & 0.681
\end{tabular}

Latency vs aggression against conspecifics

Intercept $\quad 6.204 \pm 2.288$

Aggression to

conspecifics

$0.718 \pm 0.127$

1

23.062

$<\mathbf{0 . 0 0 1}$

Size

$-1.314 \pm 0.759$

1

3.173

0.075

Probability of aggression towards predator

Intercept $\quad-4.119 \pm 1.974$

Treatment $\quad 1.666 \pm 0.726$

Size

$1.301 \pm 0.624$

7.072

0.008

5.392

$\mathbf{0 . 0 2 0}$

Probability of aggression to predator vs aggression to conspecifics

Intercept $\quad-10.764 \pm 5.753$

$\begin{array}{lllll}\text { Latency } & 1.099 \pm 0.612 & 1 & 9.584 & \mathbf{0 . 0 0 2}\end{array}$

Aggression to

conspecifics

$-0.544 \pm 0.488$

1

2.047

0.152

Size

$3.002 \pm 1.736$

1

4.853

0.028

Mixed models to test for the effect of treatment on the latency to first response to the predator and the probability to display aggressive behaviours towards the predator image (models 1 and 3). Mixed models (models 2 and 4) for the territorial contest treatment to test for the effect of aggression towards conspecifics on latency and the effect of aggression against conspecifics and latency on the probability to respond aggressively towards predators. To 
obtain normally distributed residuals we square root transformed the variables 'Latency' and 'Aggression to conspecifics'. 'Treatment': presence or absence of conspecific intruders; 'Size': standard length of test fish; 'Aggression to conspecifics': number of attacks towards the conspecific intruder in the territorial contest treatment; Reference category for the estimate 'Treatment' was the control. $N=28$ test fish and 56 observations in models 1 and 3; $N=28$ test fish and 28 observations in models 2 and 4 . Bold numbers represent significant effects $(\mathrm{p} \leq 0.05)$. 


\section{Figures}

Figure 1. Experimental set-up. Test fish were housed in tank 1, while tank 2 either contained a group of four competitors (territorial contest treatment) or was empty (control treatment). Initially, the tanks were separated by a divider, which was removed before the experiment started (left arrow, divider not shown). A computer screen was placed behind the right wall of tank 1. During the treatments the predator image moved across the computer screen on demand (indicated by the right arrow). The first third (1/3) of tank 1 , which contained the shelter, was marked with a permanent pen at the front screen of the tank. See 'Methods' sections for more details.

Figure 2: Latency to first response (square root transformed) towards the predator image (a) during the two treatments (means \pm SE shown) and (b) in relation to the level of aggression displayed towards the group (square root transformed) during the territory defence treatment. (a) $N=28$ test fish and 56 observations, (b) $N=28$ test fish and 28 observations.

Figure 3: Probability of test fish to display aggressively towards the predator image (a) in relation to the size of test fish within the territorial contest (dashed line and triangles) and the control treatment (solid line and circles), and (b) in relation to the latency to first response (square root transformed) in the territorial contest treatment. Lines represent the predicted values. 


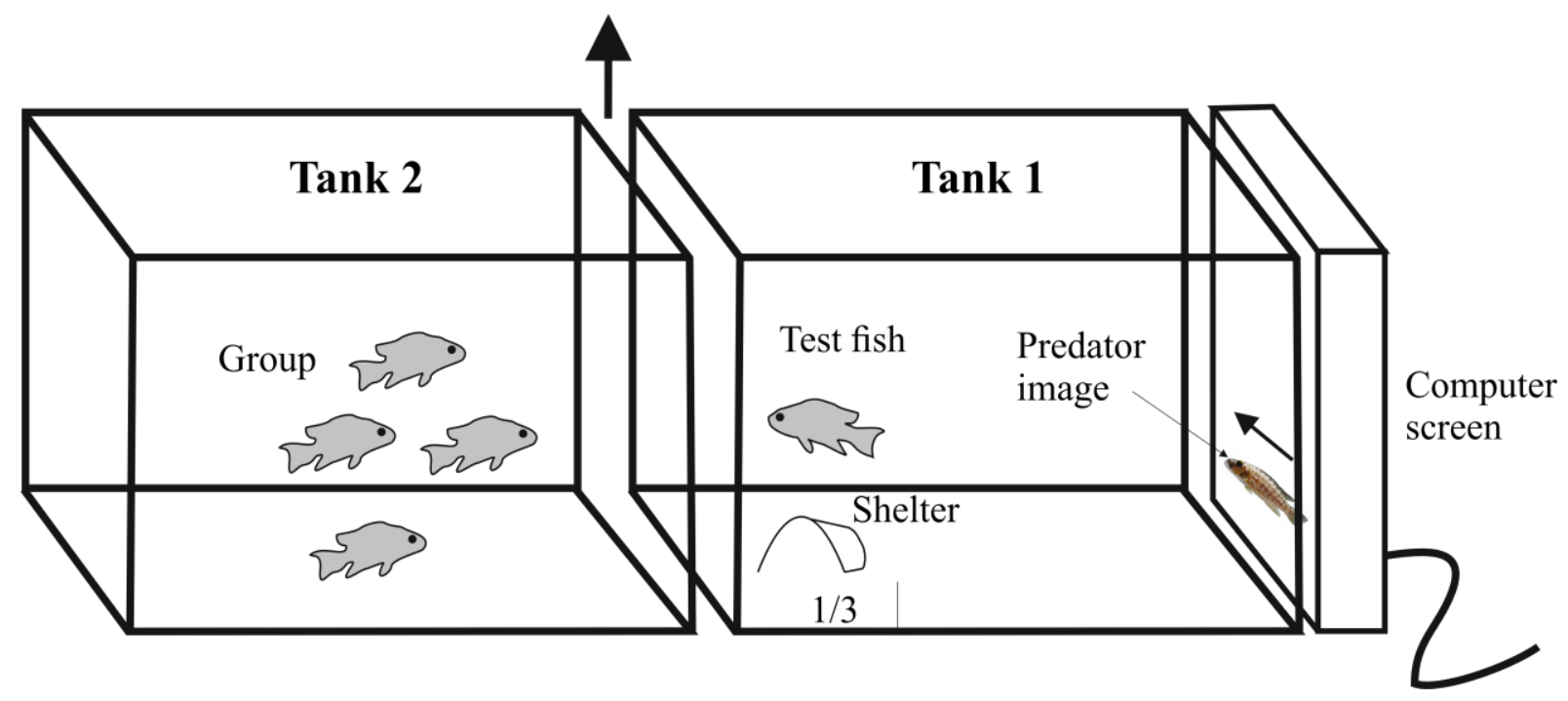

Figure 1 

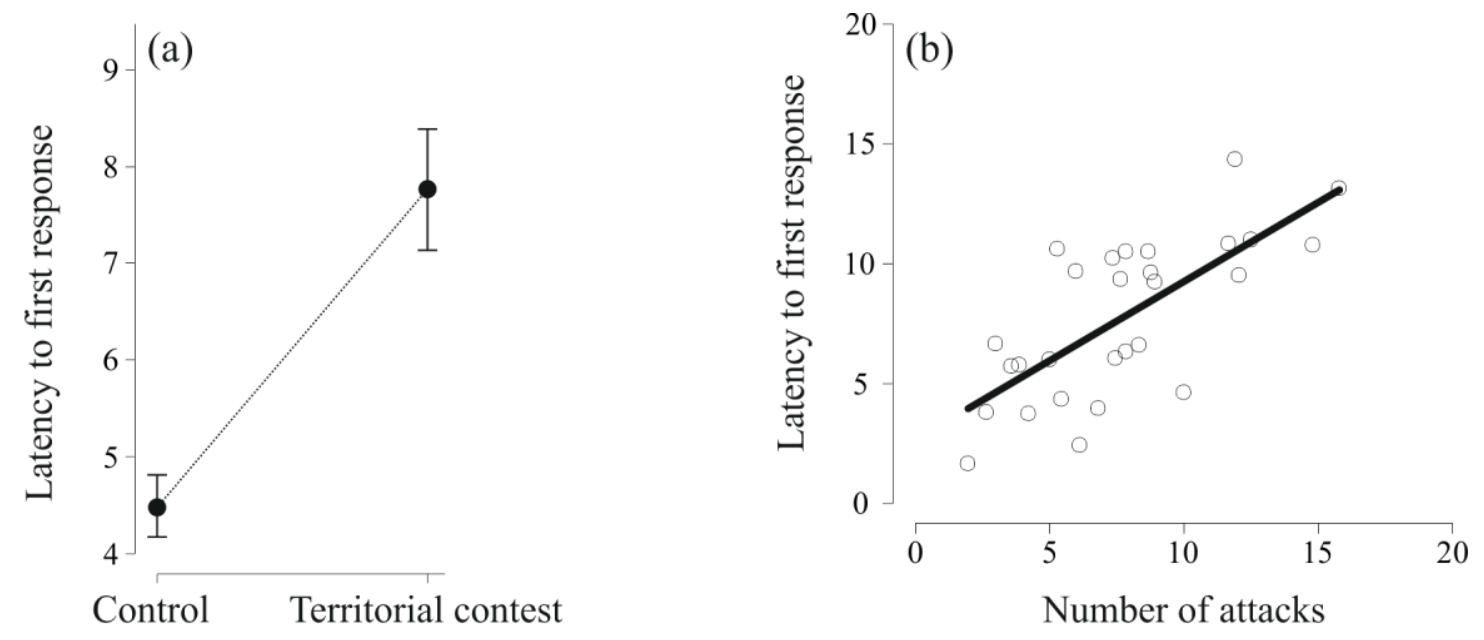

Figure 2 

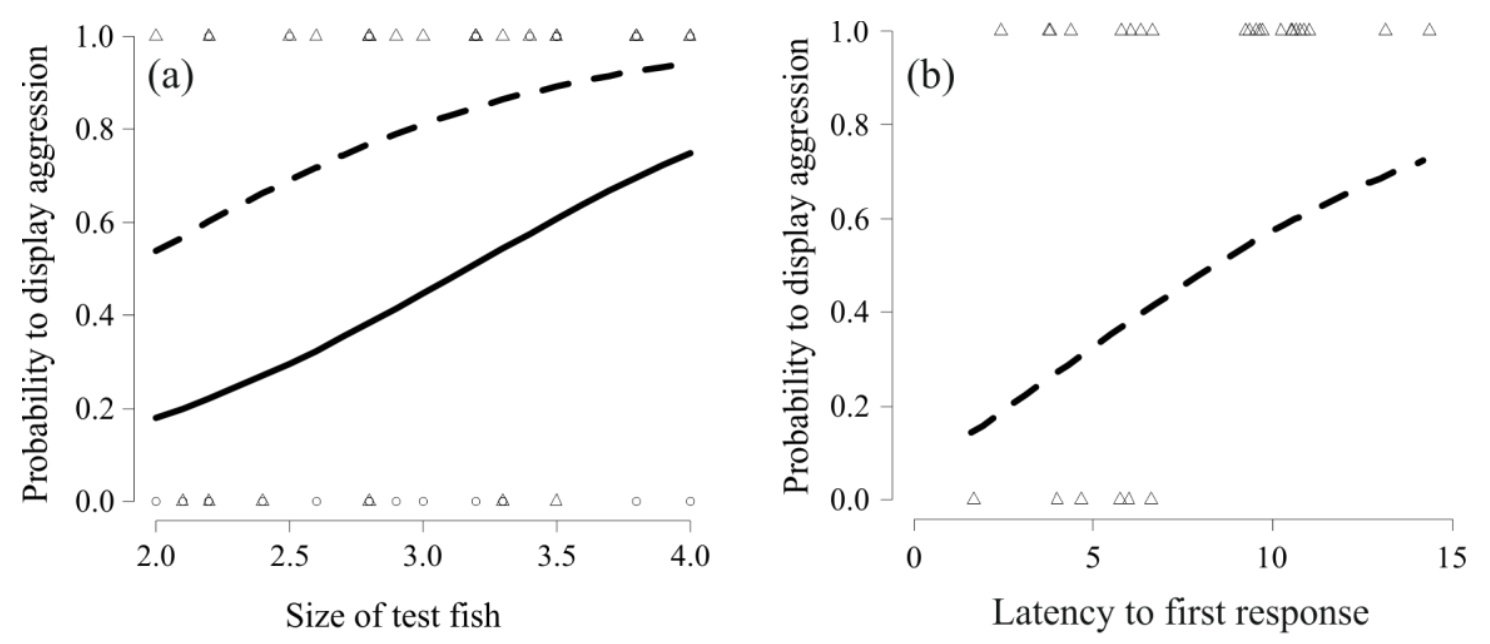

Figure 3 